\title{
Ways of improving the students' physical education
}

\author{
Irina Kalina ${ }^{1, *}$ \\ ${ }^{1}$ Kazan Federal University, 420008, Naberezhnye Chelny, Russia
}

\begin{abstract}
The article reveals the urgency and ways of improving the students' physical education providing the improvement of the structure and content of its basic components including the expansion of the information and methodological support of the educational process by means of practice-oriented content and the use of electronic and multimedia resources. Updating training programs are used to reflect the psychophysical features of the future professional activities of graduates; sportization of education (load differentiation and consideration of preferences in the choice of the type of motor activity); the use of modern fitness technologies and other means in training sessions that increase the students' motivation for the training activities. The survey results show that today, even realizing the role of physical exercises in maintaining health, the motivation of the majority of students is based on the need to get a credit for the discipline, and the development of interests is limited by the existing conditions for the organization of the training process at the university. The article also specifies the elements of the high school physical education system aimed at the improvement of its effectiveness.
\end{abstract}

\section{Introduction}

The change in the value-based objectives of modern education determined by its personality-oriented approach, humanization, strengthening of the educational process activity component, demand for practice-oriented content of the knowledge gained, etc. necessitates improving the structure and content of the basic components of high school educational system including the general physical education of students.

Search for the most effective forms of exercises, sportization of the training process, improvement of information and methodological resources, expansion of the use of aids and methods of physical education in order to increase the effectiveness of the educational process and upbringing of young professionals with the required professional and social qualities is still of current concern $[1,2,3,4]$. The urgency of this is also supported by the problem of health of the younger generation, associated, among other factors, with insufficient motor activity $[5,6]$.

It should be noted that the decrease in the desire of young people to engage in physical exercise in recent years is due not only to the growing popularity of computer games and media portals, addiction to virtual communication in social networks and economic instability causing a decrease in income for a large part of the population and the difficulties with financing of sports hobbies, but also to the imperfection of physical culture technologies used in educational institutions, their inability to develop a sustained interest in physical activity as well as in individual practice of children from an early age (and later on among young people).

Therefore, the purpose of our research was the need to identify the weak points of the organizational structure of students' physical education and concretization of its components that will allow integrating new, more effective programs into the educational process, as well as conditions and aids optimizing the solution of physical education problems at the university including the increase of students' motivation to study.

\section{Materials and methods}

The research used the following scientific methods: the analysis of scientific and methodological literature on the subject of the study, a survey of students, pedagogical observations, forming experiment, statistical methods for processing experimental data.

\section{Results and discussion}

The research was carried out on the basis of the Naberezhnye Chelny Institute of Kazan (Volga region) Federal University. Students of 1-4th courses from three faculties took part in a written survey (118 boys and 109 girls) and University graduates (93 people). All participants of the educational process were involved in the forming experiment.

The real-time correction of the educational process in the course of the experiment implementation was based on the results of systematic comprehensive monitoring of students' physical fitness according to the standards provided by the curriculum for the universities, the assessment results of theoretical and methodological knowledge of students and the level of their skills of various sports exercises developed by the department.

\footnotetext{
Corresponding author: KalinaIrinaGenn@yandex.ru
} 
Based on the results of the experimental work, pedagogical observations and the survey of students, it was found that the improvement of physical education at the university is impossible without the implementation of the following provisions.

1. Bringing work programs into compliance with the requirements of a modern educational standard which provides for the allocation of study hours not only for practical physical education of students but also formulates requirements for the level of theoretical and methodological readiness of persons receiving higher professional education in the form of general cultural competence: «be familiar with individual and methodically correct use of methods of physical education and self-education to increase adaptive body reserves, health promotion, correction of physical development».

The assessment of the educational process arrangement quality only from the standpoint of raising the level of physical and technical readiness of students is not complete because only the increase of results does not fully reflect the person's acceptance of the values of physical culture at the personal level and does not encourage everyone to continue to exercise after graduation.

Unfortunately, today we have to admit that for many students $(32 \%$ of the number of interviewed students of 1-3 courses), university training sessions are compulsory (the motivation of the majority of students is based on the need to get a credit for the discipline) that certainly does not contribute to the formation of a sustainable need for them in the future.

As evidenced by the results of the survey of 4th year students (for whom physical training classes are not included in the schedule), the percentage of students who continue to exercise regularly on their own or in any city sports sections and clubs amounts to $11.5 \%$ and the percentage of students who graduated from the university a year ago amounts only to $6.6 \%$.

In order to make the physical exercises an integral part of the graduate's life, it is necessary to form an understanding of the role of physical activity for selfimprovement and health during his studentship, as well as conscious motives for these exercises and the ability to carry out sports activities on a standalone basis $[7,8$, $9,10]$. To this end, the curriculum includes hours for lecture classes in the course of which students are taught theoretical and methodological material on the subject with the most complete amount of information about the physiological effects of systematic classes; how the motion loads are optimized depending on the physical condition of the trainee, his level of health, personal tasks and other factors; about the fundamental laws the implementation of which allows to properly plan the process of preparation to achieve the results - victories in competitions, body shaping, increasing efficiency and health.

2. Organization of independent work of students. In the process of learning (especially for the 3rd year course) the function of the teacher's direct transfer of knowledge to students should consistently decrease and the share of their self-support should grow accordingly.
It is important to take into account that the involved students are conditionally divided into three typological groups corresponding to three levels of self-support: a) imitative-passive level: the cognitive need of such students is not expressed, their activity is stimulated externally, they need the help of their group mates and teacher; b) active-research level: characterized by the free use of skills in a familiar situation (the teacher only sets a goal, and the performer himself can plan its solution); c) an intensive-creative level: in this case, significant personal motives, activity and successful application of knowledge are expressed even in an unusual situation.

Therefore, practical and methodical classes of physical education at the initial courses focus not only on the improvement of motion skills but also on the mastery of the students' methods of classes. It is necessary to thoroughly acquaint the students with the methods of directional development of individual physical qualities, methods of assessing the level of functional state and physical fitness (tests, standards, control tests in the sport chosen), methods of monitoring load parameters and assessing its adequacy, methods of restoring after training sessions, and master the skills of their use in subsequent practical classes.

Thus, the students are able to develop programs and sets of exercises for their own work taking into account individual medical parameters, tasks and ways to solve them, which is especially important for the students who have deviations in health and are engaged in special medical groups. For such students, the development of an individually oriented program of physical training and recreational activities with optimized parameters of the motion regime is provided as a test requirement. Its structure includes - the choice of the type of motor activity that meets the capabilities and preferences of the student (swimming, jogging, skiing, gymnastics), the number of independent or group lessons per week, the amount of exercises, their intensity and rest intervals between them. The intensity of the physical activities used (minimum, optimal and maximum permissible) should correspond to the functional capabilities of the body $[11,12]$.

These students gain systematic knowledge about the directed impact of various exercises on health.

3. The implementation of competence-oriented education necessitates improving the information and methodological support for physical education of students [13, 14, 15]. Printed and electronic editions developed by teachers are filled with practice-oriented content (like workbooks, training diaries, etc.) and serve not only as sources of information (complementing traditional textbooks) but also as organizers of students' individual activity and study drivers.

Moreover, application of innovative computer technologies and multimedia portals changes methods and organizational forms of education to a good quality $[2,16]$. Electronic educational sites on sports topics created and used at the University. They simplify the search and transfer of information between teachers and students, expand the availability of sources for selfeducation, create additional features for testing 
theoretical knowledge. These courses contain the presentations of lectures, educational videos and photos (for example, for a visual representation of the technique of performing motor actions), methodical recommendations and explanations, control tests and individual tasks.

Modern electronic aids and technologies are directly used in the training process for the on-line control of the functional status of students and the timely correction of the volume and intensity of loads (for example, heart rate monitors).

4. Optimization of the educational process based on the consideration of psychophysical features of the future professional activities of students (level of physical loads, psychological stress and other working factors). When choosing the aids, the kinds of sport or exercises causing the work of large grounds of muscles are preferred - swimming, skiing, athletics, gymnastics, sports games, etc.

The use of these types of motion activity makes a great effect on the development of aerobic endurance of the body which provides the increase in its efficiency and improvement of the main functional systems' activity - cardiovascular, respiratory and nervous.

The aids used in the learning process include elements of teamwork (it develops the corporate feeling), tactics (it activates thinking), develop moral and volitional qualities in changing conditions (perseverance, initiative, courage), promote coordination of movements (thereby affecting the nervous system) but at the same time, they are selected in such a way that they are available for the correct implementation by all the participants of the class.

Game and competitive elements reduce the monotony of exercises, make classes more interesting and contribute to the formation of the need for them.

5. Another important aspect is the sportization of education the aim of which is to take into account the interests of students, their features and preferences in choosing a sport when designing the conditions for differentiated education $[17,18,19]$.

Back in the 1990s., the masters of Russian physiology and theory of sports (Farfel V.S., Krestovnikov A.N., Balsevich V.K.) expressed the idea of increasing the efficiency of physical education of the younger generation through the conversion of high sports technologies [1].

However even today in most cases (with the existing organization of training sessions), students have the opportunity to be engaged only in the offered types of motion activity (this depends on the provision of the University with a sports base, the specialization of working teachers, climatic conditions and other factors). The real preferences of students in the choice of funds in most cases are not taken into account. The exceptions are classes for athletes - members of teams of the Institute. They are engaged in the sections, which for the other students, as a rule, is insufficient both in quantity and in sports orientation.

Therefore, it is necessary to include not only modern teaching methods in the educational process but also diversify it with new sports that are not used traditionally in higher schools. The experimental work demonstrated a positive experience of using frisbee (playing with a flying disc), floorball (hockey in the hall with a light plastic ball), some types of martial arts and gymnastics pilates, kalanetics, bodyflex; attractive to young people were such types of fitness as "latina", "tai-Bo", "streetdance", etc.

Besides, it is important to competently arrange not only the training process but mass competitions as well being one of its effective forms. Competitions held with high interest complement the basic curriculum and increase the activity and interest of students in classes. During the competitions the participants' character is being formed, and the teacher gets more familiar with the personality characteristics of students and becomes their tutor.

Competitions should mandatory be official in nature with rewarding the winners, they should be held regularly according to the deadlines stipulated by the competition calendar involving the sporty student core where such assistants acquire organizational and leadership skills, the sense of responsibility, the experience in effective implementation of social assignments, initiative, and team management skills. All this in the future will be useful to them in various fields of production.

6. Expansion of the material and technical base of the university designed, firstly, to give students the opportunity to choose a kind of sport for classes based on their preferences; secondly, to create such a substantive environment related to specific features of sports (stadiums, sports complexes and equipment, clothing, symbols), which among other things, will foster their aesthetic culture.

7. Since many students ( $73 \%$ of those surveyed) express a great reluctance to attend physical education classes in the mode of the school day, schools should find hours for training sessions outside the curriculum of other disciplines.

8. Improvement of teacher skills. This is achieved through qualification courses, research work and participation at conferences, by the development of new edifying aids which, in general, is intended to increase the effectiveness of the educational process.

\section{Conclusion}

Within the framework of the pedagogical experiment the potential of the university and the significant experience of the teaching staff of the Physical Education and Sport department allowed integrating modern pedagogical technologies into the educational process. It optimizes physical education and promotes the formation of such students' attitude to physical exercises that motivates them to go in for sports in extracurricular activities.

Implementing all the aspects listed above in the materials of the article in a natural unity contributed to the students' competence improvement reflected in the results of the final control of theoretical and methodological knowledge level of the "Physical culture and sport" discipline (16\% improvement compared to 
previous year students' results) and in the assessment of mastering technical elements of some sports (in particular, volleyball and basketball) - $72 \%$ positive changes of the tested students.

The formed demand for physical activity, knowledge of the development of physical qualities and improvement of technical skills in the chosen kind of sport, knowledge of the fundamental laws of arranging individual classes contribute to the successful implementation of the training process in practice, healthy lifestyle, and the success of future specialists in life and profession in the future.

The work is performed according to the Russian Government Program of Competitive Growth of Kazan Federal University.

\section{References}

1. V.K. Balsevich, Theory and practice of physical culture, 3, 21-40 (2004)

2. V.O. Kashuba, N.L. Golovanova, Physical education of students, 22 (2), 57-62 (2018)

3. L.V. Shuba, V.V. Shuba, Physical education of students, 21 (6), (2017)

4. A.I. Zagrevskaya, Theory and practice of physical culture and sports, 11, 51-54 (2012)

5. A. Hanssen-Doose, C. Albrecht, S. Schmidt, German journal of exercise and sport research, 48 (4), 530-543 (2018)

6. J.D. Svystun, V.M. Trach, Kh.E. Shavel, Pedagogics psychology medical-biological problems of physical training and sports, 21 (6), 301-307 (2017)

7. A.I. Golubev, G.N. Golubeva, et al., National academy of managerial staff of culture and arts herald, 4 (2), 281-285 (2017)
8. V.P. Guba, N.N. Chesnokov, Innovative methods of physical culture (Physical culture, Moscow, 2008)

9. C. Kerner, V. Goodyear, American journal of health education, 48 (5, SI), 287-297 (2017)

10. M.A. Krivtsova, M.I. Shepeleva, Physical culture of students: materials of the 60th St. Petersburg interuniversity scientific.-prakt. conf., 45-47 (2011)

11. I.G. Kalina, R.A. Aidarov, Journal of history culture and art research, 6(4), 673-679 (2017)

12. S.L. Popel, G.A. Pyatnychuk, D.V. Pyatnichuk, V.V. Maystruv, Physical education of students, 21 (6) (2017)

13. R.A. Aidarov, I.G. Kalina, Modern Journal of Language Teaching Methods, 7 (9.1), 343-347 (2017)

14. A. Slobodanka, ECER, The past, the present and the future of educational research, URL: http://www.eera-

ecer.de/ecerprogrammes/conference/19/network/470 (date of access: 2014)

15. A. Tufekčić, Basic determinants of producing a modern textbook. Meto-dički obzori, 7 (2), 119-126 (2012)

16. E.O. Ivanova, I.M. Osmolovskaya, SHS Web of Conferences, 29, 01055 (2016)

17. A.P. Bondarchuk, Sportization of physical education (Olympia Press, Moscow, 2007)

18. L.I. Lubysheva, Physical culture: education, training, 4, 6-8 (2015)

19. R.M. Raevsky, Sportization of physical education as a problem of modernity (Physical education and sport, Moscow, 2008) 